\title{
A Study on Professional Development Scale for Master of Full-time Education (PDSM-FE)
}

\author{
Hongcui ZHU \\ College of Education, Capital Normal University, Beijing, China
}

\begin{abstract}
This study developed and validated Professional Development Scale for Master of Full-time Education (PDSM-FE) to assess the students' training quality, using the methods of literature research, questionnaires, interviews and data statistics. The PDMS-FE includes three dimensions, namely, teachers' professional disposition, professional knowledge and professional capability. Factor analysis was done on the 40 items developed in this study. 32 items were found to be factorialy valid. The PDSM-FE was also found to be reliable with a coefficient of 0.936 . The results of administration show that the professional development of Masters of full-time education (MFE) at Capital Normal University is good.
\end{abstract}

KEYWORD: Master of full-time education; professional development; professional disposition; professional knowledge; professional capability

It is widely acknowledged that teacher is the basic factor of education in China. Especially in the current 10 years, how to train the high quality preservice teachers has long be concerned. From the development of international teacher education, there exist three tendencies: knowledge-oriented teacher training, technology-oriented teacher training and research-oriented teacher training. Of the three, the pre-service teachers who are educated in the last way have strong critical thinking and creative abilities. However, whatever phase of teacher education is, the mode of pre-service teacher training is based on classroom teaching.

Although this kind of teacher education mode can relieve the shortage of teachers, it is not efficient for student teachers to have enough educational practice, which hinders the professional development of preservice teacher education greatly. In order to change the worse situation and improve the quality of preservice teacher education, from the 1980s to 1990 s of the last century, Professional Development Schools (PDS) in America and "Partnership Schools" in England were established to make student teachers to have about a year's "clinical practice" in elementary and secondary schools before their beginning of occupation, which can greatly link the gap between theory and practice and advance the professionalization of teacher education. In China, at the beginning of 21 century, with the tendency of international teacher education, Beijing Normal University, Northeast Normal University, Nanjing Normal University and Capital Normal University began to cooperate with schools to explore the reform on the integration of teacher education. However, what's the efficiency of this kind of training mode? It's a pity that fewer scales can be found to assess the professional development for MFE in China. Therefore, the main aim of this study was set to do the following:

1) Develop a Professional Development Scale for Master of full-time education (PDSM-FE).

2) Determine the factorial validity of the items in the PDSM-FE.

3) Determine the internal consistency reliability of the items in the PDMS-FE.

\section{THE PDSM-FE CONSTRUCT}

In order to develop PDSM-FE, the related literature has been researched, including the Professional standards from America, England and China. Then the theoretical framework of PDSM-FE was constructed. The details can be seen as follows.

\subsection{Research on Teachers' Professional standards}

The Professional Development Scale for Master of full-time education constructed in this study referred to the teachers' professional standards of America, England and China. We have done the literature from the following aspects: the content, the framework and the observation points et al.

First of all, from the view of content, National 
Council for the Accreditation of Teacher Education (NCATE) of America enacted a standard for candidate teachers in 1954 which includes: to be familiar with the teaching contents; to understand the effective teaching strategies; to reflect one's own teaching practice and adjust one's own teaching; to offer teaching to the students from different cultural backgrounds; to be supervised by the mentor and to be able to apply educational technology in teaching (Xudong Zhu, 2011). Meanwhile, Interstate New Teacher Assessment and Support Consortium (INTASC) of America also issued a standard of new teacher in 1997 which comprises 10 key criterions. They contain the following aspects, namely, the subject knowledge; the students' teaching; the students' diversity; the teaching strategies; the learning environment; the ways of communication; the teaching plans; the strategies of evaluation; the teachers' reflection and professional development and the cooperative relationship (INTASC, 1997). Each standard includes three parts: Knowledge; Disposition and Performance. Both standards offer an effective framework for assess pre-service teachers' professional development. The professional standard of qualified teachers in England (2006) also includes three parts, namely, teachers' professional quality; teachers' professional knowledge and understanding and teachers' professional skills. All of the contents are based on the theory of teachers' professional development. It suggests that teachers' professional knowledge and skills are of importance in teachers' professional evaluation. Teachers' behavior is a criterion for teachers' Ethics and responsibility. On December $12^{\text {th }}$, 2011, the Chinese Ministry of Education decreed "the Professional Standards of Preschool Teachers", "the Professional Standards of Primary school Teachers" and "the Professional Standards of High school Teachers"( the Chinese Ministry of Education, 2011) too. From the years of 2011 to 2012, all these standards were put into practice on a trial basis. The basic concepts are as follows:

1) The students should be the main focus.

2) The teachers' ethics should be put in the first place.

3) The teachers' professional skills should be emphasized.

4) The teachers should have awareness of lifelong learning.

The main framework comprises 3 dimensions, 14 concrete indexes and 61 observation points. The contents cover professional ideas and teachers moral, which is made up of professional understanding and self-identity; the attitudes and behavior to the students; the attitudes and behavior to education and teaching; the personal accomplishment and behavior; the professional knowledge, which consists of educational knowledge, subject knowledge, pedagogical content knowledge and general knowledge; professional skills, which is composed of teaching design, teaching implementation, classroom management and educational activities, educational and teaching assessment, communication and cooperation and reflection and development.

In addition, from the framework of the standards, in general, the professional standards at home and abroad all adopt three-dimensional structure. Although the cultural backgrounds are various in different countries and the specific contents are diverse, the framework of a tri-grade evaluation index system is very obvious. The first-class index is on professional field which means that teacher as a profession is supposed to possess basic knowledge and skills, including teachers' professional knowledge, professional skills and professional attitudes and moral. Teachers' professional knowledge and skills are connected with whether teachers' teaching can enhance the development of the students. Teachers' professional attitudes and moral, such as professional moral and professional autonomy is connected with whether teachers have lifelong learning abilities and potential. The second index is a general elaboration of professional field which can summarize the basic contents of all the teachers' professional evaluation criterion. It is a state of a professional evaluation criterion which is supposed to be. The third index is the most detailed requirements of the teachers' professional evaluation standard which can be measured and appraised, thus judging whether the teachers reached the professional standard. All the analysis has laid a solid foundation to the construction of Professional Development for master of full-time education (PDSM). All of these researches have laid solid foundation for the development of the PDSM-FE in this paper.

\subsection{Theoretical framework of PDSM-FE}

The instrument-Professional Development for master of full-time education (PDSM) was developed from literature review, survey questionnaires and interviews. The instrument is an inventory structured on 3 dimensions, namely, teachers' professional teachers' professional disposition, professional knowledge and professional capability and 11 sub-dimensions. The dimension of professional disposition contains professional morals, arrangement of professional development and communication and cooperation. The dimension of professional knowledge includes self-knowledge, students' knowledge, educational and teaching knowledge and curriculum knowledge of subjects. The dimension of professional skills consists of educational instructional implementation and educational and instructional evaluation (See Figure1). 


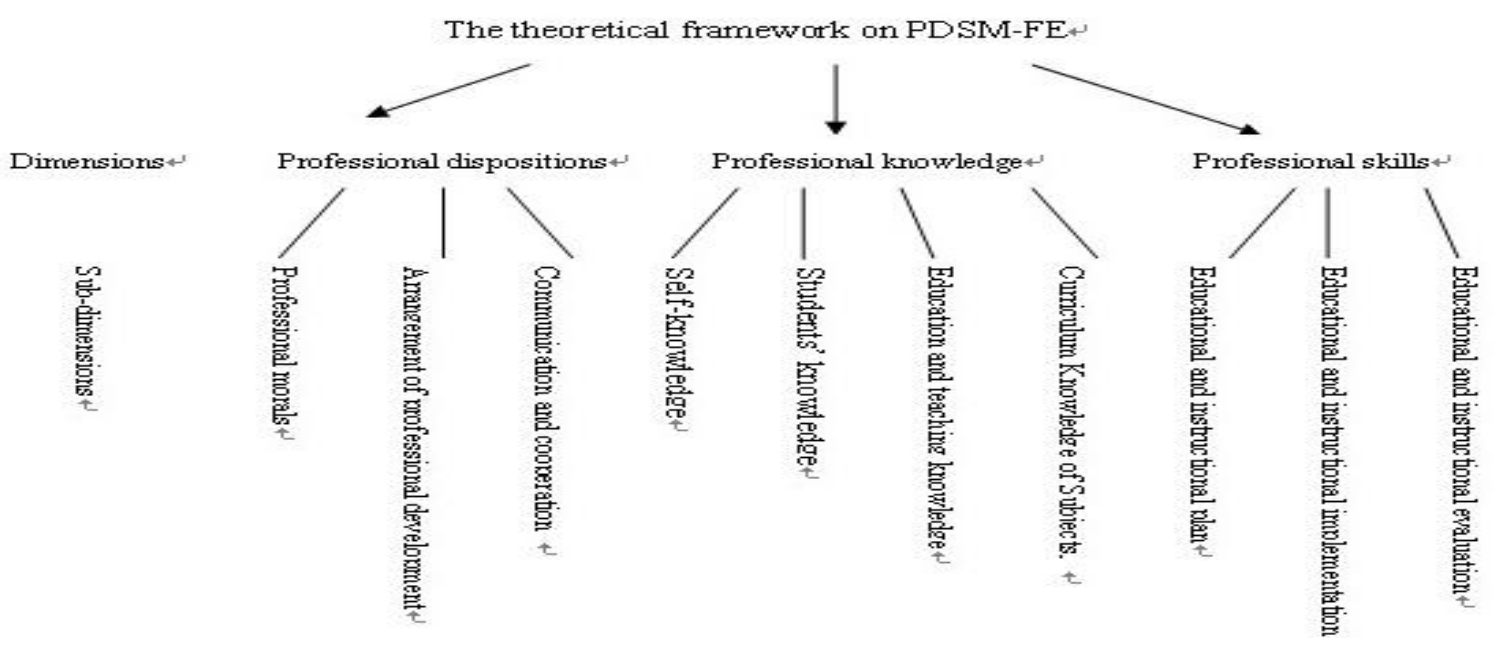

Figure 1. The theoretical framework on PDSM-FE

\section{METHODS}

\subsection{Participants}

There are three administrations of the questionnaires, of which the previous two are used for screening the items of the scale, and the last one is to determine whether the items screened have good reliability and validity, to test whether the three-dimensional structure is reasonable, better fitting the real data and to measure the professional development of the preservice teachers with the degree of MFE.

The former two participants are pre-service teachers with the degree of MFE at Capital Normal University which is one of the 12 test units of Master of Education of approved by Chinese Ministry of Education. The number of the first participants for pre-test is about 71 enrolled in 2011 and the second one is about 111 admitted in 2009, 2010. The survey adopted the methods of cluster sampling and the student teachers did the survey through the internet.

The number of third participants is 152 who were admitted by Capital Normal University in 2012. We also used the platform of internet to give out the questionnaires and got 136 pieces (response rate: $89 \%$ ). These participants have studied in Capital Normal University for half a year and will be interns in senior high schools of Beijing for about two weeks. From the aspect of whether the respondents are normal students when they were still undergraduates, 27 percent of them are not normal students and 73 percent of them are normal students; From the aspect of where the student teachers come from, 37 percent of them are from Beijing and 63 percent of them are from other places; From the aspect of sexual distinction, 14 percent of them is male students and 86 percent of them is female students; The students' major contains 15 categories, namely, Chinese, Maths, English, Physics, Chemistry, Biology, History, Geography, Politics, Music, Fine arts, Information Technology Education, Preschool Education, Education Management and Mental Health Education. Of them, the proportion of the Maths, Chinese and English covers 16 percent, 15 percent and 12 percent respectively.

\section{Procedures}

The questionnaire is designed through the following steps. Firstly, a literature review was done, which is on teachers' professional standards of America, England and China and other related data. After that, some interviews and open-ended questionnaires were done. On the basis of the above data and analyzing pre-service teachers' learning and their practice in senior high schools, "the initial professional development questionnaire on MFE" was developed.

Secondly, some experts of teacher education were asked to prove and revise the initial questionnaire which is about whether the contents of the questionnaire fit the current learning condition of MFE and whether it is comprehensible. This initial questionnaire was administrated on the student teachers, who were admitted in 2011 and took back 71 questionnaires, using the methods of item analysis and reliability test to screen the items which are not significant, simultaneously revising the questionnaires.

Thirdly, the revised questionnaires were administrated on the student teachers enrolled in 2009 and 2010 through the internet and took back 111 pieces. Based on the results of data analysis and referring to the literature and analyzing the records of interviews, the author revised the questionnaires again.

Finally, a total of 32 items were chosen to constitute the research instrument-PDSM-FE, consisting of three dimensions, of which, the first dimension includes 8 items which measure the preservice teachers' professional dispositions, the second dimension comprises 9 items which reflects the pre-service teachers' professional knowledge, and the third dimension cover 15 items which test pre-service teachers' professional skills. These general items are presented in Table 1. 
Table 1. Professional Development Scale for Master of full-time education (PDSM-FE)

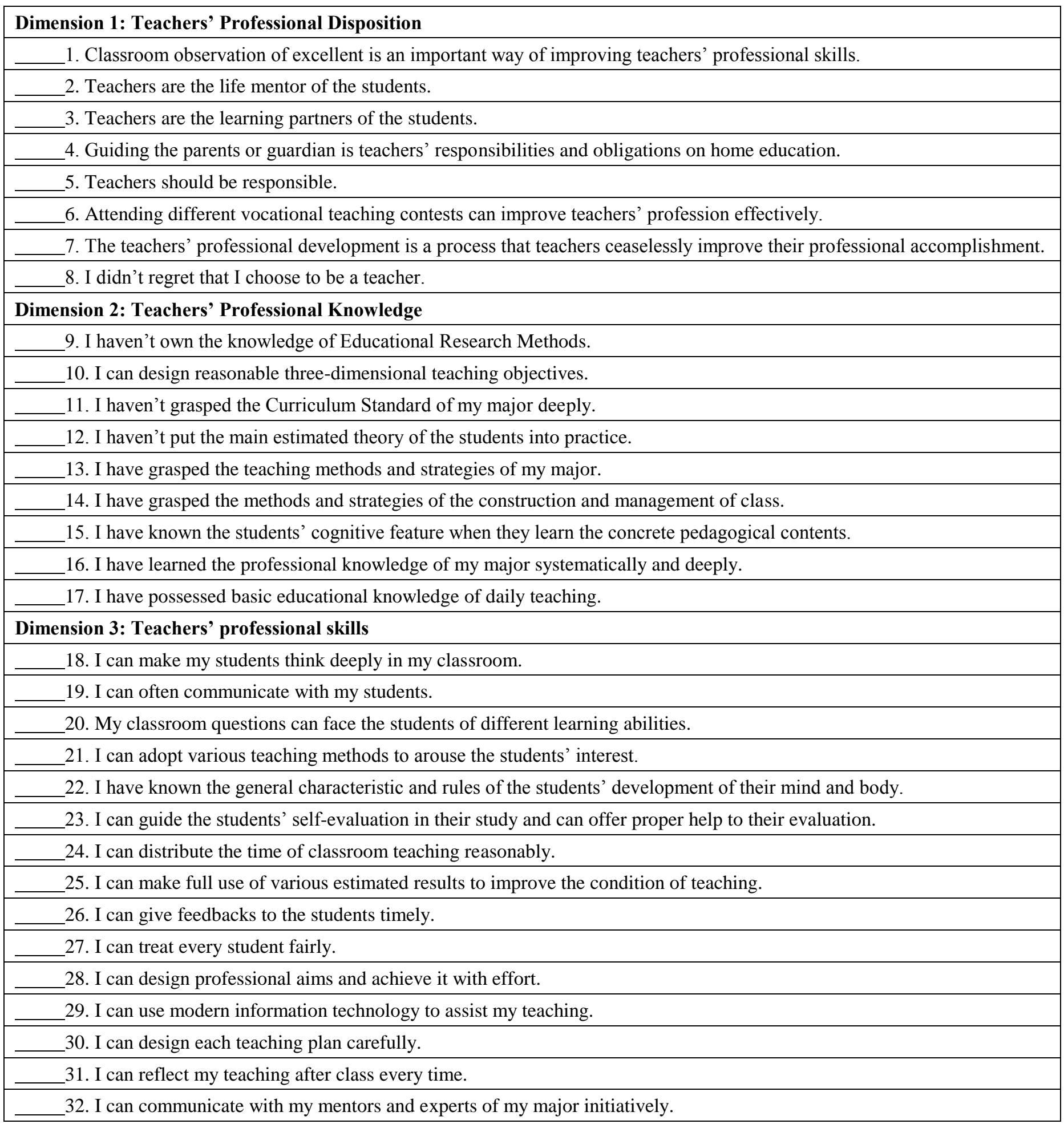

\subsection{Data Analysis}

The data was analyzed using the SPSS 16.0 Version and Excel computer software. Statistical techniques included correlation analysis for testing the reliability of the scale, exploratory factor analysis for testing the validity of the scale, analysis of variance (ANOVA) to examine whether the correlation coefficient of the scale has significant differences and regression analysis to check whether there are significant differences in the students' gender etc.

\section{RESULTS}

\subsection{Alpha Reliabilities}

The coefficient of Cronbach alpha was used to analyze the inner reliability of the scale. The results can be seen in Table 2. The coefficient of Cronbach alpha is 0.936. And the coefficient of Cronbach alpha of every dimension is from 0.788 to 0.923 which shows that the subscale and total scale both have better reliabilities. So all the data shows that the scale constructed in this paper has perfect reliability and inner homogeneity. 
Table 2. The intramural consistency reliability of three dimensions and the total scale

\begin{tabular}{|c|c|c|c|c|}
\hline & Dimension 1 & Dimension 2 & Dimension 3 & $\begin{array}{c}\text { Total } \\
\text { Scale }\end{array}$ \\
\hline $\begin{array}{c}\text { The } \\
\text { Coefficient } \\
\text { Cronbach } \alpha\end{array}$ & 0.788 & 0.854 & 0.923 & 0.936 \\
\hline
\end{tabular}

\subsection{Validity Estimates}

The method of exploratory factor analysis was used to test the structure validity of this scale. The value of Bartlett's sphericity test is that $\mathrm{x}^{2}=2.401 \mathrm{E} 3$ $(\mathrm{P}<0.001)$ which shows that it has significant differences and also indicates that the variables have common factors which can be analyzed by the methods of factor analysis. Meanwhile, the index of $\mathrm{KMO}=0.894$ which also reveals that the sample data fits in with factor analysis. On the premise of limiting the dimensions of factors, the data is analyzed by principal components analysis, extracted the common factors (The requirement is that the eigenvalue must be greater than 1) to obtain the initial load matrix and used the maximum variance oblique rotation to get the final load matrix The results of Table 3 suggest that the factors' explanation of the total variance has reached 51.03 percent and the range of the factor load is from 0.465 to 0.760 . All these analysis shows that the extracted factors can better fit the original data and the three dimensions (namely, teachers' professional knowledge, teachers' professional skills and teachers' professional disposition) constructed in this paper coincides with the theoretical hypothesis

\subsection{Correlation coefficient Analysis}

This article uses multiple ANOVA to assess the correlations of each dimension and the total scale and each dimension to test the construct validity of this scale. The cross-correlation coefficient of total scale and subscale can be seen in Table 4.
Table 3. The Analysis of factors after rotation on PDSM-FE

\begin{tabular}{|c|c|c|c|}
\hline \multirow[b]{2}{*}{ Items } & \multicolumn{3}{|c|}{ Factor loading } \\
\hline & $\begin{array}{l}\text { Professional } \\
\text { dispositions }\end{array}$ & $\begin{array}{l}\text { Professional } \\
\text { knowledge }\end{array}$ & $\begin{array}{c}\text { Professional } \\
\text { skills }\end{array}$ \\
\hline $\mathrm{T} 1$ & 0.742 & & \\
\hline $\mathrm{T} 2$ & 0.673 & & \\
\hline T3 & 0.664 & & \\
\hline $\mathrm{T} 4$ & 0.647 & & \\
\hline T5 & 0.625 & & \\
\hline T6 & 0.564 & & \\
\hline T7 & 0.478 & & \\
\hline $\mathrm{T} 8$ & 0.453 & & \\
\hline T9 & & 0.711 & \\
\hline $\mathrm{T} 10$ & & 0.675 & \\
\hline $\mathrm{T} 11$ & & 0.663 & \\
\hline $\mathrm{T} 12$ & & 0.645 & \\
\hline T13 & & 0.558 & \\
\hline $\mathrm{T} 14$ & & 0.534 & \\
\hline $\mathrm{T} 15$ & & 0.519 & \\
\hline T16 & & 0.460 & \\
\hline $\mathrm{T} 17$ & & 0.426 & \\
\hline $\mathrm{T} 18$ & & & 0.795 \\
\hline T19 & & & 0.774 \\
\hline $\mathrm{T} 20$ & & & 0.757 \\
\hline $\mathrm{T} 21$ & & & 0.744 \\
\hline $\mathrm{T} 22$ & & & 0.670 \\
\hline $\mathrm{T} 23$ & & & 0.662 \\
\hline $\mathrm{T} 25$ & & & 0.657 \\
\hline T26 & & & 0.650 \\
\hline $\mathrm{T} 27$ & & & 0.635 \\
\hline T28 & & & 0.573 \\
\hline T29 & & & 0.521 \\
\hline T30 & & & 0.517 \\
\hline $\mathrm{T} 31$ & & & 0.468 \\
\hline T32 & & & 0.459 \\
\hline $\begin{array}{c}\text { Eigenvalue } \% \\
\text { of variance }\end{array}$ & 1.948 & 2.739 & 11.641 \\
\hline $\begin{array}{l}\text { Accumulated } \\
\text { Rates }\end{array}$ & $6.09 \%$ & $14.65 \%$ & $51.03 \%$ \\
\hline
\end{tabular}

Table 4. The cross-correlation coefficient of total scale and subscale $(\mathrm{N}=136)$

\begin{tabular}{|c|c|c|c|}
\hline & Professional knowledge & Professional skills & Professional disposition \\
\hline Professional knowledge & 1 & & \\
\hline Professional skills & $0.380^{* *}$ & 1 & \\
\hline Professional disposition & $0.493^{* *}$ & $0.723^{* *}$ & 1 \\
\hline Professional development & $0.672^{* *}$ & $0.857^{* *}$ & $0.938^{* *}$ \\
\hline
\end{tabular}

The double stars $(* *)$ show that all the correlation coefficient has reached the significance of 0.01 .

The data of Table 4 indicates that the correlation coefficient of every dimension and the total score is between 0.672 and 0.938 which is middle and high correlated. This results show that every dimension of this scale has coherent construct validity and simultaneously has some differences. The mutual correlation coefficient of each dimension is between 0.380 and 0.723 , which is low and middle correlate. So the discriminate validity of it is more reasonable. In general, not only each dimension of this scale has 
an accordant construct validity, but also it can be different from one another, so we can say that the framework of this scale strongly fits in with the requirements of formation.

\section{DISCUSSIONS AND CONCLUSIONS}

The primary goal of this research was to develop a "Professional Development scale for Master of fulltime education" to measure the training efficiency of pre-service teachers with high reliability and validity. The results of the study reported above indicate that this goal was achieved.

Additionally, it was determined that the reliability estimate of this instrument was 0.936. And the coefficient of Cronbach alpha of each dimension is from 0.788 to 0.923 . The content validity of the instrument is very strong because the experts of teacher education, in-service teachers and the author, all joined together to design, test and revise the items of the scale for several times. The methods of exploratory factor analysis suggest that the original three-dimensional theoretical hypothesis fit the real data, for the three factors' explanation of the total variance has reached 51.03 percent. At this point, it appears that the scale is both reliable and valid.

All in all, this scale generated in this paper has higher reliability and validity which can be used for assessing the pre-service teachers' professional development and in some degree has theoretical value and practical prospect. Meanwhile, we also found that the items of factors on three-dimensional framework were unbalanced, which will be adjusted and revised in the future research.

\section{FUNDING}

This article is part of the research achievement whose name is research on the construction of the partnership between universities and school which is funded by the key project of humanities and social science research base of Chinese Ministry of education. (The project number is 12JJD88000)

\section{REFERENCES}

[1] Xudong Zhu. (2011). The Research on standard system of Teacher Education. Beijing: the Press of Beijign Normal University.

[2] INTASC. (1997). Inter-state New Teacher Assessment and Support Consortium Standard Draft. Available at: http://www.Google. Com. Cited on December 162002.

[3] Standard for Initial Teacher Education. (2006). Retrieved from: http:// www. gtcs. org.uk/ standard-initial-teachereducation. aspx.

[4] Chinese Ministry of Education. (2012). The Professional Standard of elementary school teachers. Retrieved from: http:// www. moe. gov.cn/publicfiles/ business/ htmlfiles/ moe/ s6991/ xxgk_145603.html.

[5] Chinese Ministry of Education. (2012). The Professional Standard of elementary school teachers. Retrieved from: http:// www. Moe.gov.cn/ publicfiles/business/ htmlfiels/ moe/ s69991/xxgk_145603.htmi.

[6] Chinese Ministry of Education. (2012). The Professional Standard of high school teachers. Retrieved from: http:// www. Moe. gov.cn/ publicfiles/ business/ htmlifles/ moe/ s6991/xxgk_145603.html. 